\title{
Low Shear Rheological Behaviour of Two-Phase Mesophase Pitch
}

\author{
Shatish Ramjee, Brian Rand*, Walter W. Focke \\ SARChI Chair of Carbon Technology and Materials, Department of Chemical Engineering University of \\ Pretoria, Pretoria, South Africa, 0002
}

\begin{abstract}
:
The low shear rate rheology of two phase mesophase pitches derived from coal tar pitch has been investigated. Particulate quinoline insolubles (QI) stabilised the mesophase spheres against coalescence. Viscosity measurements over the range 10 to $10^{6} \mathrm{~Pa}$.s were made at appropriate temperature ranges. Increasing shear thinning behaviour was evident with increasing mesophase content. At low mesophase contents the dominant effect on the near Newtonian viscosity was temperature but at higher contents it was the shear rate; temperature dependence declined to near zero. The data indicated that agglomeration could be occurring at intermediate mesophase volume fractions, 0.2-0.3. The Krieger-Dougherty function and its emulsion analogue indicated that in this region the mesophase pitch emulsions actually behaved like 'hard' sphere systems and the effective volume fraction was estimated as a function of shear rate illustrating the change in extent of agglomeration. At the higher volume fractions approaching the maximum packing fraction, which could only be measured at higher temperatures, the shear thinning behaviour changed in character and it is considered that this is possibly due to shear induced deformation and breakup of dispersed drops in the shear field.
\end{abstract}

\section{Nomenclature list}

$\eta \quad$ viscosity

Pa.s

$\eta_{T} \quad$ temperature dependent viscosity (Arrhenius model)

Pa.s

$K_{\eta_{T}} \quad$ pre-exponential factor

Pa.s

$E_{\eta} \quad$ activation energy

${\mathrm{J} . \mathrm{mol}^{-1}}^{-1}$

$R \quad$ universal gas constant

J. $(\operatorname{mol} . \mathrm{K})^{-1}$

$T$ temperature

K

$\mathrm{K}_{\mathrm{p}} \quad$ power-law flow consistency index

Pa.s ${ }^{\mathrm{n}}$ 


$\begin{array}{lll}\dot{\gamma} & \text { shear-rate } & \mathrm{s}^{-1} \\ \mathrm{n} & \text { power-law flow-behaviour index } & - \\ \varphi & \text { volume fraction of filler } & - \\ \phi_{\mathrm{m}} & \text { maximum packing volume fraction } & - \\ {[\eta]} & \text { intrinsic viscosity } & - \\ \eta_{0} & \text { zero-shear viscosity } & \text { Pa.s } \\ \eta_{\infty} & \text { infinite-shear viscosity } & \text { Pa.s } \\ \lambda & \text { Carreau-Yasuda viscous relaxation constant } & \mathrm{s} \\ \mathrm{a} & \text { Carreau-Yasuda model constant } & - \\ K & \text { viscosity ratio }\left(\eta_{d} / \eta_{c}\right) & - \\ \eta_{\mathrm{r}} & \text { reduced viscosity }\left(\eta^{\prime} \eta_{c}\right) & - \\ \eta_{\mathrm{c}} & \text { continuous phase viscosity } & \mathrm{Pa} . \mathrm{s} \\ \eta_{\mathrm{d}} & \text { dispersed phase viscosity } & \mathrm{Pa} . \mathrm{s} \\ \mathrm{Ca} & \text { capillary number } & - \\ \mathrm{r} & \text { drop radius } & \mathrm{m} \\ \sigma & \text { interfacial tension } & \mathrm{N} . \mathrm{m}^{-1}\end{array}$

\section{Introduction}

Petroleum, coal-tar and mesophase pitches are key precursor materials in the production of a wide range of engineering carbon and graphite materials. Their rheological properties are critical to many of the processing operations [1] such as extrusion/moulding of pitch-coke mixtures, impregnation, matrix in $\mathrm{C} / \mathrm{C}$ composites, fiber spinning and mesophase sintering.

The thermal transformation from the isotropic pitch to the mesophase state and to coke is well documented, occurring via the nucleation and growth of spherical nematic discotic droplets. The process is one of continual change in rheological character from the near Newtonian behaviour of the initial isotropic precursor through various viscoelastic stages to the solid coke product. The rheological properties of pitch were reviewed by Rand [1]. Isotropic and mesophase pitches have been studied by Bhatia et al. [2] and Blanco et al. [3] among others. Pitches are complex viscoelastic materials [1][4]. At low temperatures isotropic pitch is a glassy material, the glass transition temperature increasing with heat treatment temperature as the average molecular mass increases. Viscoelastic behaviour is observed at temperatures close to the glass transition temperature [4], but at higher 
temperatures the behaviour is approximately Newtonian, although there have been observations of a yield stress and plastic viscosity (Bingham type behaviour) in some cases. Additives such as carbon black and sulphur have been reported to accentuate this behaviour [2]. Blanco et al [3] found that in two-phase pitches both the anisotropic pitch and its filtered isotropic fraction showed non-Newtonian behaviour. The shear-thinning behaviour observed was attributed to the large molecules present in the isotropic phase that are formed during heat treatment. Air-blowing of isotropic pitch was also found by Menendez et al. [5] to increase elasticity at low frequencies under dynamic oscillatory conditions, and attributed to the molecular crosslinking. Daji et al. [6] also observed increased low frequency elasticity in heat-treated isotropic pitches.

The glass transition temperature of the mesophase is higher than that of isotropic pitch due to the generally higher molecular mass [1]. Mesophase also shows non-Newtonian behaviour at temperatures above the glass transition and greater elasticity than isotropic pitch [7]. Mesophase displays a polydomain microstructure [8], and it has been suggested that the increasing shear rate reduces the size of the domain to a finer texture in $100 \%$ mesophase pitch [9]. The transition is characterised by a sudden drop in viscosity which elongates the domain of the microstructure [10]. The elastic response of the mesophase material appears to be associated with the underlying microstructure. Finer textures exhibit lower elasticity [8].

Much less is known about the rheological behaviour of two-phase systems comprising continuous isotropic pitch containing dispersed mesophase. During transformation to mesophase, the pitch materials show shear-thinning character, but at these temperatures they also behave as emulsions and the dispersed mesophase droplets can be deformed [11]. It has been shown that such two phase systems show non-Newtonian behaviour even at lower temperatures closer to softening [12] [3]. Blanco et al. [3] observed that for a coal tar pitch with a mesophase content approaching 50\%, both separated isotropic and partially anisotropic material exhibit shear-thinning characteristics and reach an infinite-shear plateau viscosity. In all cases, the separated isotropic phase was less viscous than the two phase mixture [3].

Two phase pitches with dispersed mesophase and continuous isotropic pitch will behave as suspensions or emulsions depending upon whether the temperature is below or above the glass transition temperature of the mesophase. The aim of this study was to investigate in 
more detail than hitherto the flow behaviour of such two phase systems at different temperatures and to establish the extent to which conventional approaches to the characterisation of suspensions and emulsions are applicable. A coal tar pitch containing quinoline insoluble particulates was selected and heat treated to various temperatures to develop the mesophase dispersion. It was expected that the QI would assist in stabilising the mesophase as approximately spherical particles/droplets. The rheological behaviour of suspensions and emulsions relevant to the interpretation of results is presented in the discussion section.

\section{Experimental}

\subsection{Preparation of Pitches}

A coal tar pitch (MP110) with a ring and ball softening temperature of $110{ }^{\circ} \mathrm{C}$ was heattreated under nitrogen and unstirred at temperatures and times, listed in Table 1. All batches of the same nominal treatment were cooled, ground and mixed thoroughly to develop a homogeneous mixture.

\subsection{Characterisation of Pitches}

\subsubsection{Composition}

Solubility in toluene and quinoline was determined by the method of Blanco et al [13]. The carbon yield was determined via thermo-gravimetric analysis in nitrogen as the residue at $1000{ }^{\circ} \mathrm{C}$. Elemental analysis was carried out by standard methods to give $\mathrm{C} / \mathrm{H}$ atomic ratio.

\subsubsection{Rheometry}

Rheological experiments were conducted in heated nitrogen on an Anton Paar MCR301 rheometer fitted with a heated convection hood using a parallel plate configuration with a 25 $\mathrm{mm}$ spindle. Viscosity data were obtained by shear-rate controlled experiments, from $0.01 \mathrm{~s}^{-1}$ to $100 \mathrm{~s}^{-1}$, isothermally at various temperatures around the softening temperature. A fresh sample was used for each temperature run. Repeat runs under the same conditions showed the same rheological character in the sense that the viscosity vs. shear-rate plots were similar. 
However, sometimes the data were displaced to higher or lower viscosity than the average but the shifts were significantly less than the changes due to temperature.

\subsubsection{Characteristic temperatures}

The glass transition temperature was measured as the change in expansion coefficient [1] by thermomechanical analysis in nitrogen on a TMA Q400 with a flat-ended macro-expansion probe. A Perkin Elmer DMA 8000 was also used to investigate the glass transition. The powdered sample was inserted into a metal jacket, whose mechanical properties are not within the measurement range of the pitch, and examined in single cantilever configuration by oscillation at $0.1 \mathrm{~Hz}$ at a heating rate of $1{ }^{\circ} \mathrm{C} \min ^{-1}$ to $200{ }^{\circ} \mathrm{C}$. The temperature of the $\tan \delta$ peak was determined. This is often used as a measure of the glass transition in polymer systems; however it is perhaps more likely the mid-point of the transition, where a material changes from solid-like to more liquid like behaviour.

\subsubsection{Mesophase content}

The mesophase content of the samples was determined by polarised light optical microscopy on fused and polished samples ( $1 \lambda$ retarder plate). The mesophase content was estimated by analysis of the area of the spherically shaped particles on a grey scale image. At least 7 images were used for calculating the content for each sample.

\section{Results and Discussion}

\subsection{Composition of the pitch samples}

The compositional characteristics of the samples are shown in Table 1. The parameters all vary with increasing mesophase content as would be expected from previous knowledge of such systems. In terms of accounting for the change in rheological properties it is more precise to use compositional characteristics than the preparation conditions. Hence, the $\mathrm{C} / \mathrm{H}$ ratio and the mesophase content have been adopted as the most appropriate compositional characteristics. The QI content of the starting pitch was $10 \%$ by weight due to insoluble particulates emanating from the coking process. This mass fraction increased during heat treatment due to pyrolysis of the pitch by an amount calculated from the mass difference. The 
QI content also increased due to thermally generated insoluble species and this nonparticulate QI can be estimated from the data in Table 1.

Table 1: Characteristic Compositional Parameters for the pitch and its heat treated products

\begin{tabular}{|c|c|c|c|c|c|c|}
\hline Sample & $\begin{array}{l}\mathrm{C} / \mathrm{H} \\
\text { ratio }\end{array}$ & $\begin{array}{l}\mathrm{TI} \\
(\%)\end{array}$ & $\begin{array}{l}\text { QI } \\
(\%)\end{array}$ & $\begin{array}{c}\text { non-part. QI } \\
(\%)\end{array}$ & $\begin{array}{l}\text { CY } \\
(\%)\end{array}$ & $\begin{array}{c}\text { Mesophase } \\
(\text { Vol\%) }\end{array}$ \\
\hline MP110 & 1.83 & 34 & 10 & 0 & 44 & 0 \\
\hline MP110HT350 & 1.87 & 38 & 14 & 4 & 49 & 0 \\
\hline MP110HT375 & 1.88 & 40 & 20 & 9 & 52 & 0 \\
\hline MP110HT400 & 1.98 & 47 & 23 & 12 & 58 & 13 \\
\hline MP110HT437 & 2.05 & 58 & 33 & 21 & 65 & 27 \\
\hline MP110HT425 & 2.09 & 60 & 33 & 18 & 70 & 26 \\
\hline MP110НT425T6 & 2.10 & 62 & 39 & 27 & 71 & 38 \\
\hline MP110HT437T6 & 2.20 & 68 & 44 & 31 & 73 & 49 \\
\hline
\end{tabular}

\# MP110HTxxxTy: MP110 neat pitch; HT = heat treated; $\mathrm{xxx}=$ heat treatment temperature in ${ }^{\circ} \mathrm{C}$; and $\mathrm{Ty}=$ heat treatment time in $\mathrm{h}$ when more than $1 \mathrm{~h}$ was used. TI = Toluene Insolubles, QI = Quinoline Insolubles, non-part. $\mathrm{QI}=$ non-particulate quinoline insoluble, $\mathrm{CY}=$ Carbon Yield.

Figures 1 (a)-(d) show the development of mesophase. Only those samples heated beyond $400{ }^{\circ} \mathrm{C}$ had significant amounts of mesophase. The mesophase spheres increased in amount as the $\mathrm{C} / \mathrm{H}$ ratio increased. The particulate $\mathrm{QI}$ progressively accumulates at the surface of the mesophase spheres. This is significant as it changes the interfacial tension and tends to restrict coalescence. The effect of particulates and inclusions on the growth and structure of liquid crystals has been reviewed by Soule and Rey [14]. These authors also discussed the effect of non-mesogen constituents on the microstructural development of mesophases [15]. The sample at the highest $\mathrm{C} / \mathrm{H}$ ratio (2.20) had a mesophase content of $49 \%$ but showed little evidence of coalescence into large mesophase domains. The spherical character was largely retained. In all cases the continuous phase is the isotropic pitch. However, both the composition and properties of each phase will change progressively with heat treatment and the values shown in Table 1 refer only to the overall composition. 


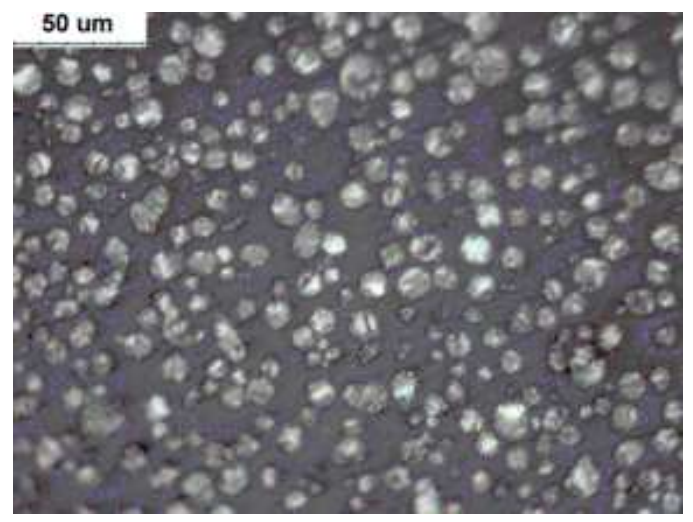

(a)

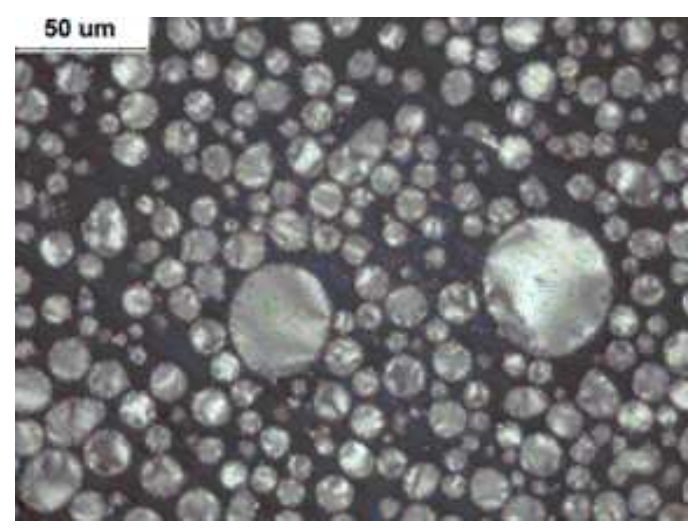

(c)

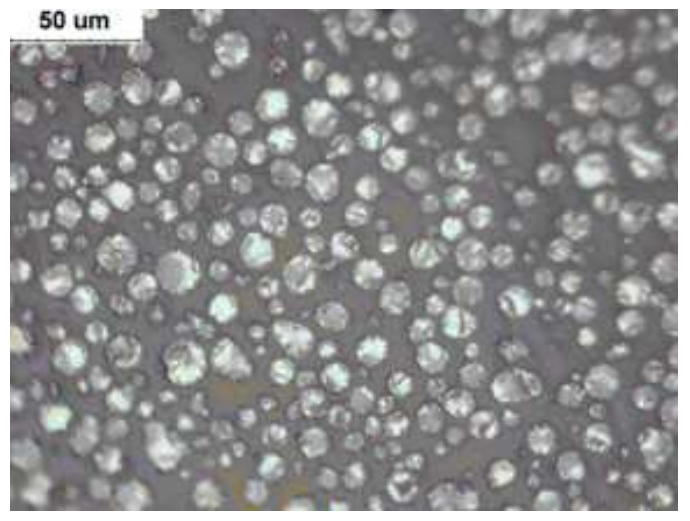

(b)

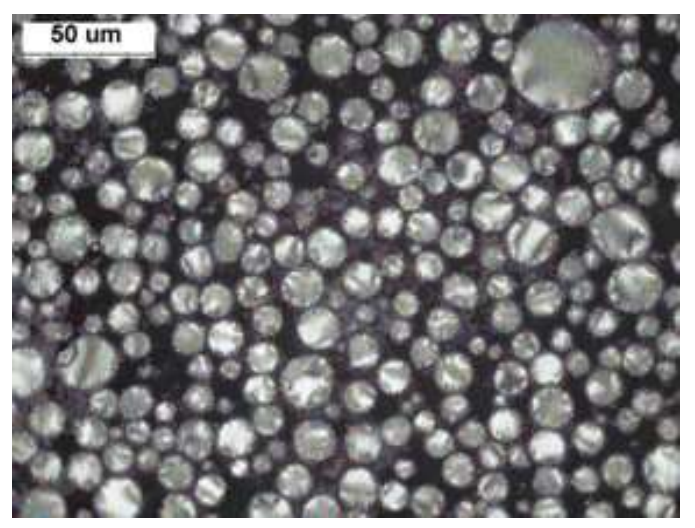

(d)

Figure 1 (a) MP110HT437, mesophase pitch with 27 vol\% mesophase and $\mathrm{C} / \mathrm{H}=2.05$

(b) MP110HT425, mesophase pitch with $26 \mathrm{vol} \%$ mesophase and $\mathrm{C} / \mathrm{H}=2.09$

(c) MP110HT425T6, mesophase pitch with $38 \mathrm{vol} \%$ mesophase and $\mathrm{C} / \mathrm{H}=2.10$.

(d) MP110HT437T6, mesophase pitch with 49 vol\% mesophase and $\mathrm{C} / \mathrm{H}=2.20$ ).

\subsection{Characteristic temperatures}

Table 2 shows the characteristic temperatures. The glass transition temperature from the TMA experiment increased with $\mathrm{C} / \mathrm{H}$ ratio reflecting the glass transition of the continuous phase, as the amorphous material would relax first and be the first to be detected. Benn [16] compared the transition temperatures for two-phase systems and the isotropic phase separated by centrifugation and found them to be the same within experimental error. 
Table 2: Characteristic Temperatures for the pitch and its heat treated products

\begin{tabular}{ccccc}
\hline Sample & $\begin{array}{c}\mathrm{C} / \mathrm{H} \\
\text { ratio }\end{array}$ & $\begin{array}{c}\mathrm{TMA} \mathrm{T}_{\mathrm{g}} \\
\left({ }^{\circ} \mathrm{C}\right)\end{array}$ & $\begin{array}{c}\mathrm{DMA} \mathrm{T}_{\tan \delta}{ }^{1} \\
\left({ }^{\circ} \mathrm{C}\right)\end{array}$ & $\begin{array}{c}\mathrm{DMA} \mathrm{T}_{\tan \delta}^{2} \\
\left({ }^{\circ} \mathrm{C}\right)\end{array}$ \\
\hline MP110 & 1.83 & 38 & 59 & - \\
MP110HT350 & 1.87 & 52 & 76 & - \\
MP110HT375 & 1.88 & 51 & 74 & - \\
MP110HT400 & 1.98 & 68 & 94 & - \\
MP110HT437 & 2.05 & 67 & 95 & 135 \\
MP110HT425 & 2.09 & 79 & 112 & - \\
MP110HT425T6 & 2.10 & 81 & 118 & 140 \\
MP110HT437T6 & 2.20 & 66 & 100 & 138 \\
\hline
\end{tabular}

\# MP110HTxxxTy: MP110 neat pitch; HT = heat treated; $\mathrm{xxx}=$ heat treatment temperature in ${ }^{\circ} \mathrm{C}$; and Ty $=$ heat treatment time in $\mathrm{h}$ when more than $1 \mathrm{~h}$ was used, $\mathrm{T}_{\mathrm{g}}=$ glass transition temperature of isotropic phase, $\mathrm{T}_{\tan \delta}{ }^{1}=$ $\tan \delta$ peak temperature of isotropic fraction, $\mathrm{T}_{\tan \delta}{ }^{2}=\tan \delta$ peak temperature of mesophase fraction.

The $\tan \delta$ values in Table 2 locate the mid-point of the glass to liquid transition, whereas the TMA $\mathrm{T}_{\mathrm{g}}$ value reflects the onset of this transition. The samples with significant amounts of mesophase showed evidence of two transitions the second, attributed to the mesophase, sometimes appearing as a shoulder on the main peak. An example is shown in Figure 2. So, although the glass transition onset temperature of the mesophase has not been determined, it is clear that at temperatures at and above the second $\tan \delta$ the mesophase in principle is in a viscous fluid state and this will be significant for any measurements made above this temperature.

\subsection{Shear Rheology}

\subsubsection{Flow curves}

The flow curve at each temperature for the starting pitch, Figure 3, is approximately horizontal, i.e. almost independent of shear rate indicating near Newtonian behaviour at moderate shear rates. At the very highest shear rates some shear thinning is evident. Nevertheless, temperature is the most dominant factor. Viscosity changed by more than three orders of magnitude in the temperature range $80{ }^{\circ} \mathrm{C}$ to $130{ }^{\circ} \mathrm{C}$. The other isotropic samples and the predominantly isotropic one with only 13 vol\% mesophase and $\mathrm{C} / \mathrm{H}=1.98$ (MP110HT400) displayed similar behaviour but with increasing shear thinning character 
becoming evident in the high shear rate region. These results are presented in the supplementary material.

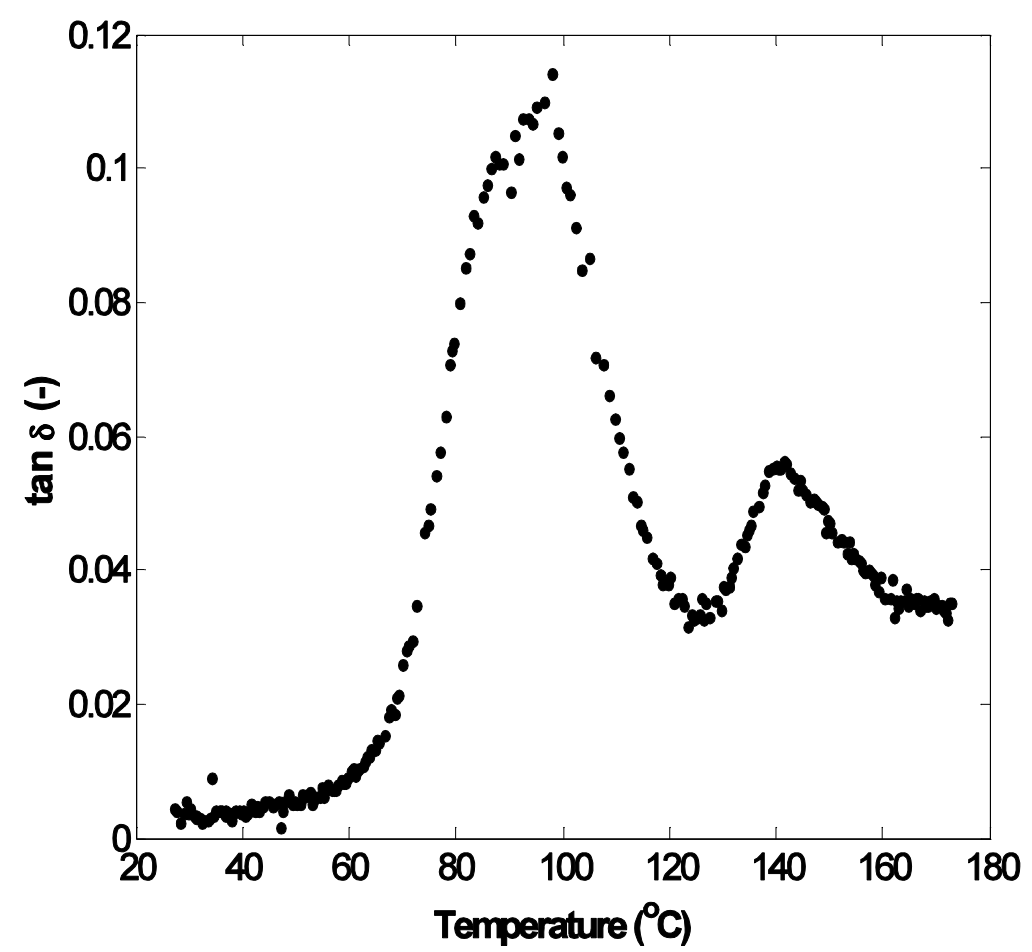

Figure 2: Example of two tan $\delta$ peaks from DMA analysis of MP110HT437 with 27 vol \% mesophase and $\mathrm{C} / \mathrm{H}=2.05$.

The flow curves for the remaining, mesophase-containing materials, shown in Figures 4 to 7 are different all displaying a shear thinning character from the very lowest shear rates, the extent increasing with mesophase content. Whereas with the isotropic pitch materials, the viscosity changed by 3 or 4 orders of magnitude with temperature and the variation with shear rate at a constant temperature was small, with the mesophase systems the reverse was the case. For these systems the viscosity changed from 1 to 3 orders of magnitude with shear rate (in some cases by more than 3) at constant temperature and the effect of temperature became gradually less important. This is discussed in more detail below. 


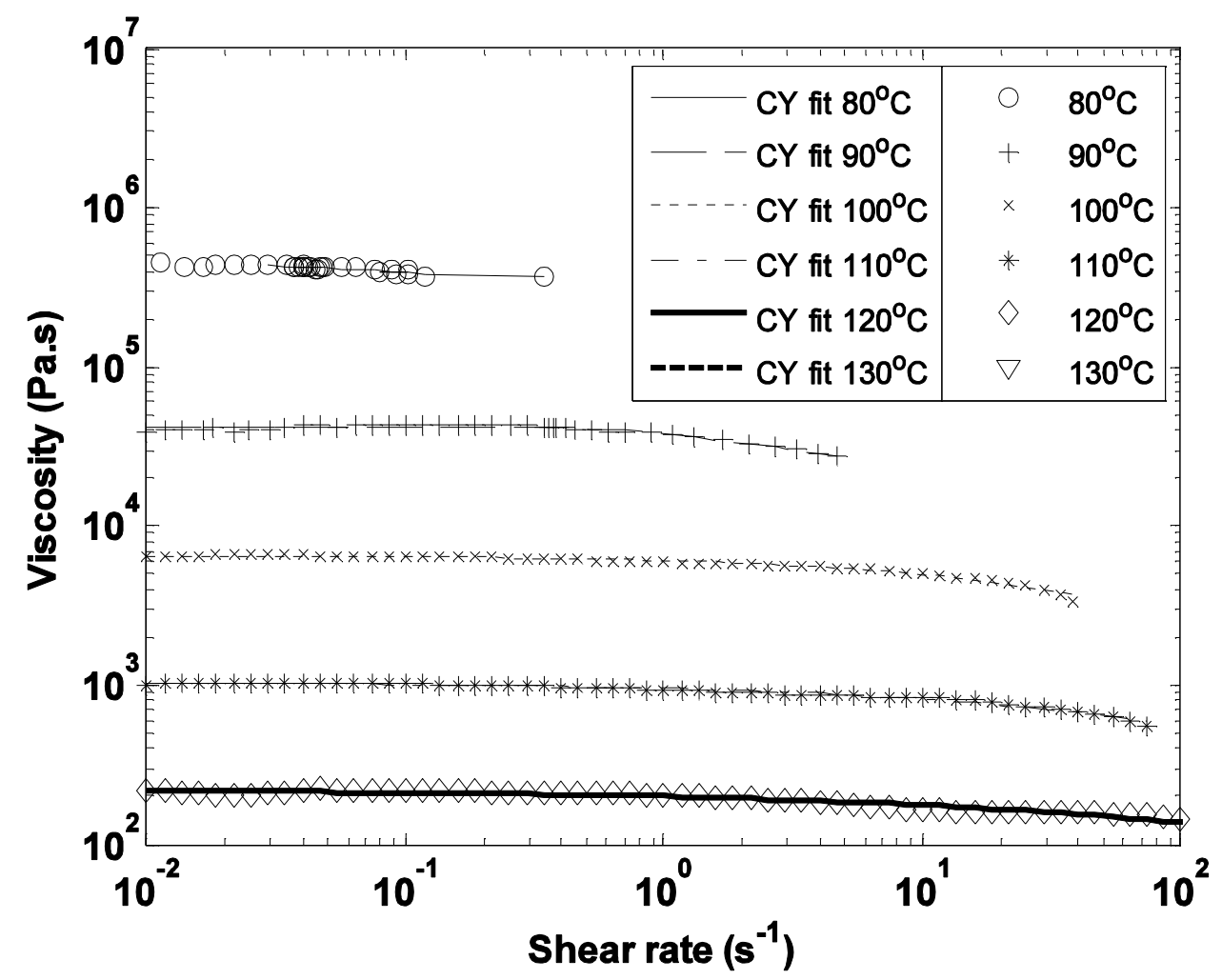

Figure 3: Flow curves of the isotropic starting pitch, $\mathrm{MP} 110$ with $\mathrm{C} / \mathrm{H}=1.83$

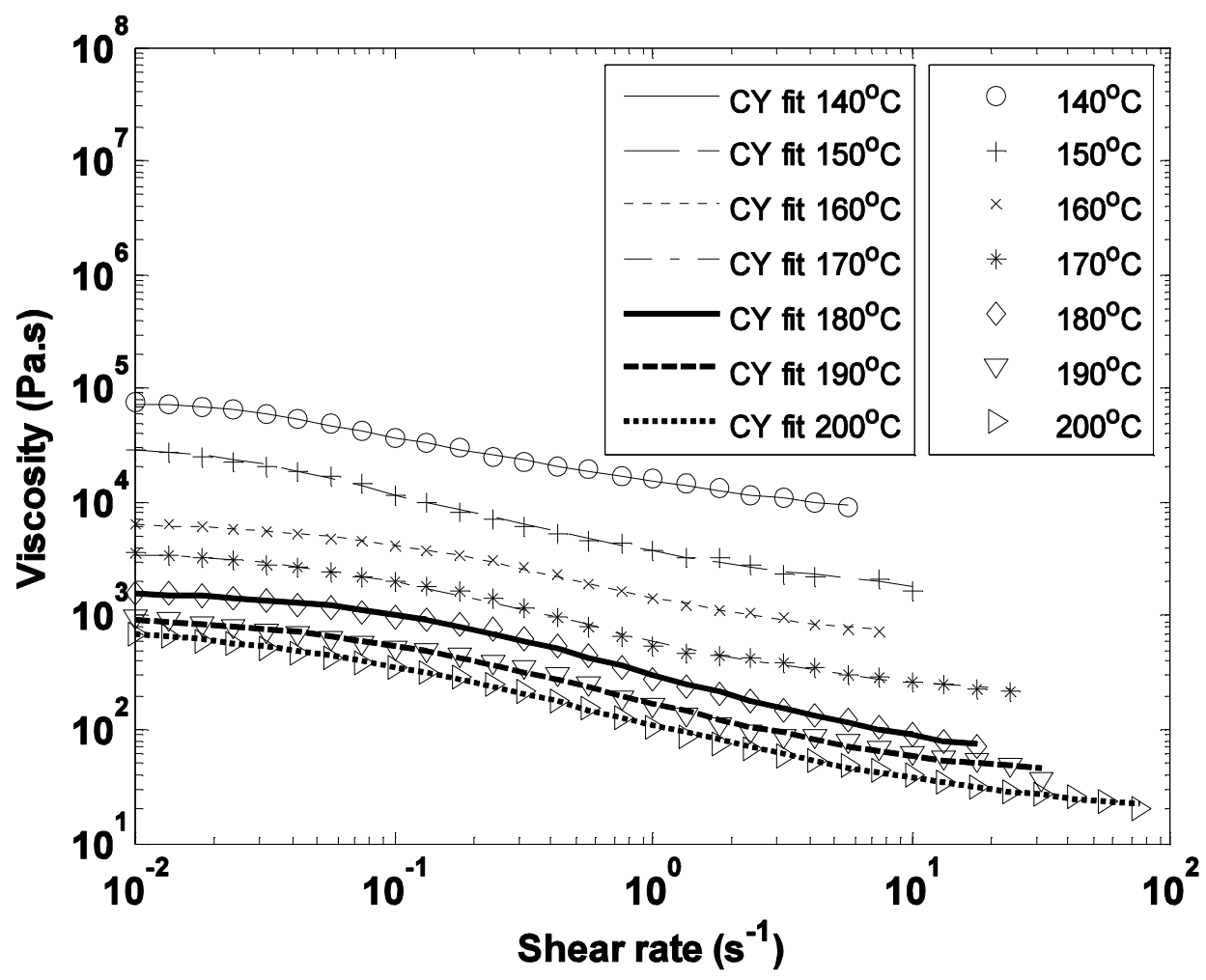

Figure 4: Flow curves of mesophase pitch MP110HT437 with mesophase content of 27 vol\% mesophase and $\mathrm{C} / \mathrm{H}=2.05$. 


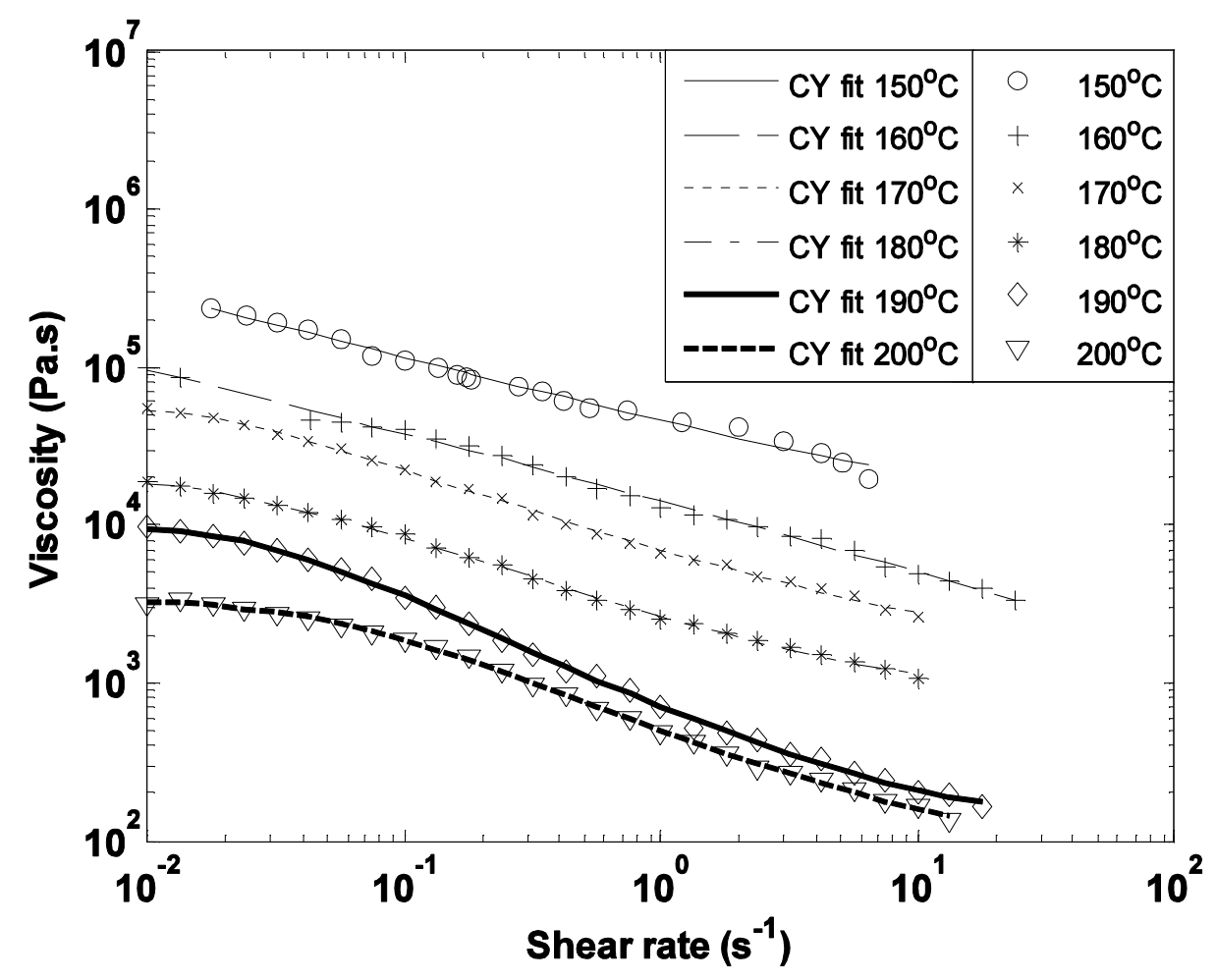

Figure 5: Flow curves of mesophase pitch MP110HT425 with mesophase content of 26 vol\% and $\mathrm{C} / \mathrm{H}=2.09$.

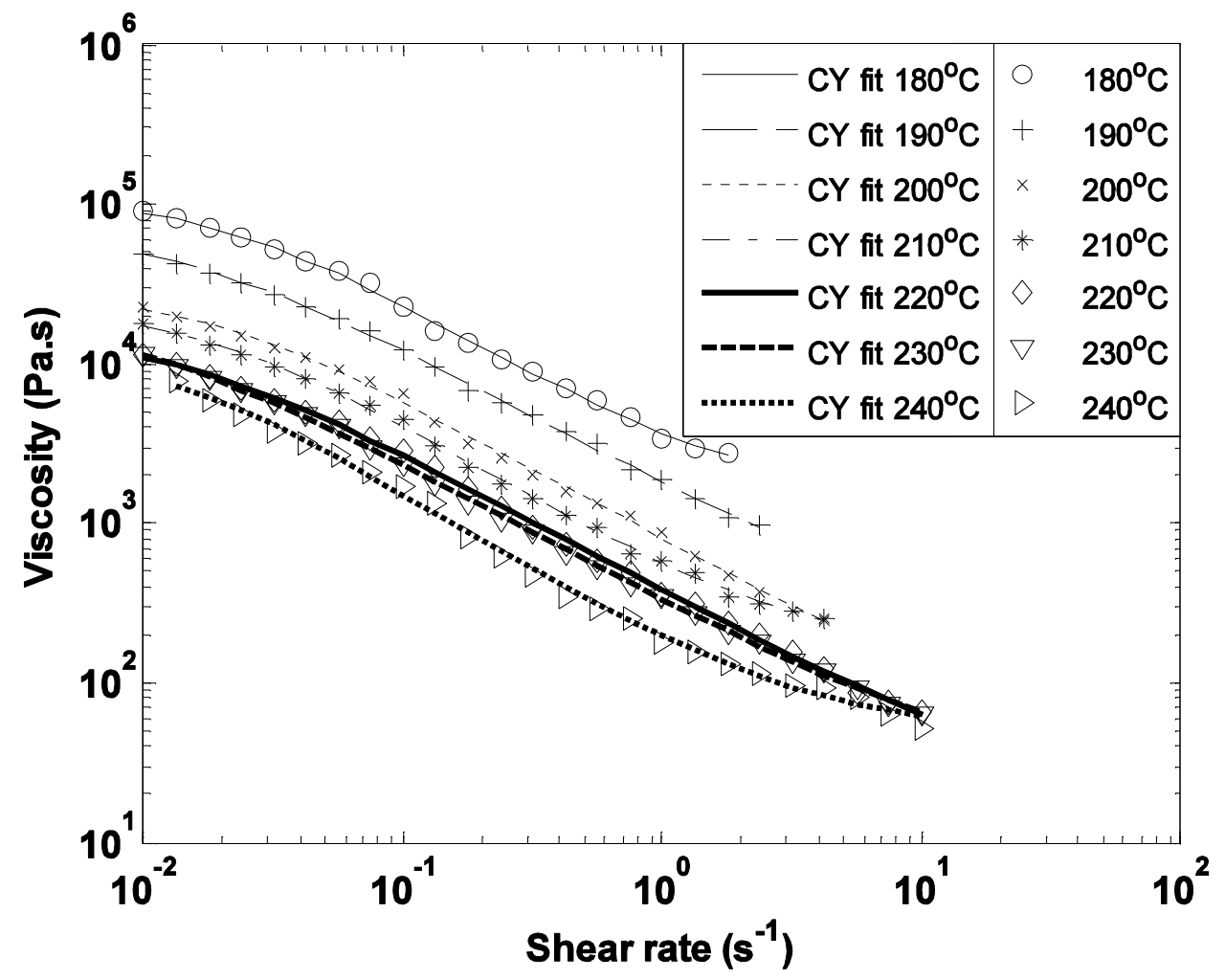

Figure 6: Flow curves of mesophase pitch MP110HT425T6 with mesophase content of 38 vol\% and $\mathrm{C} / \mathrm{H}=$ 2.10 . 


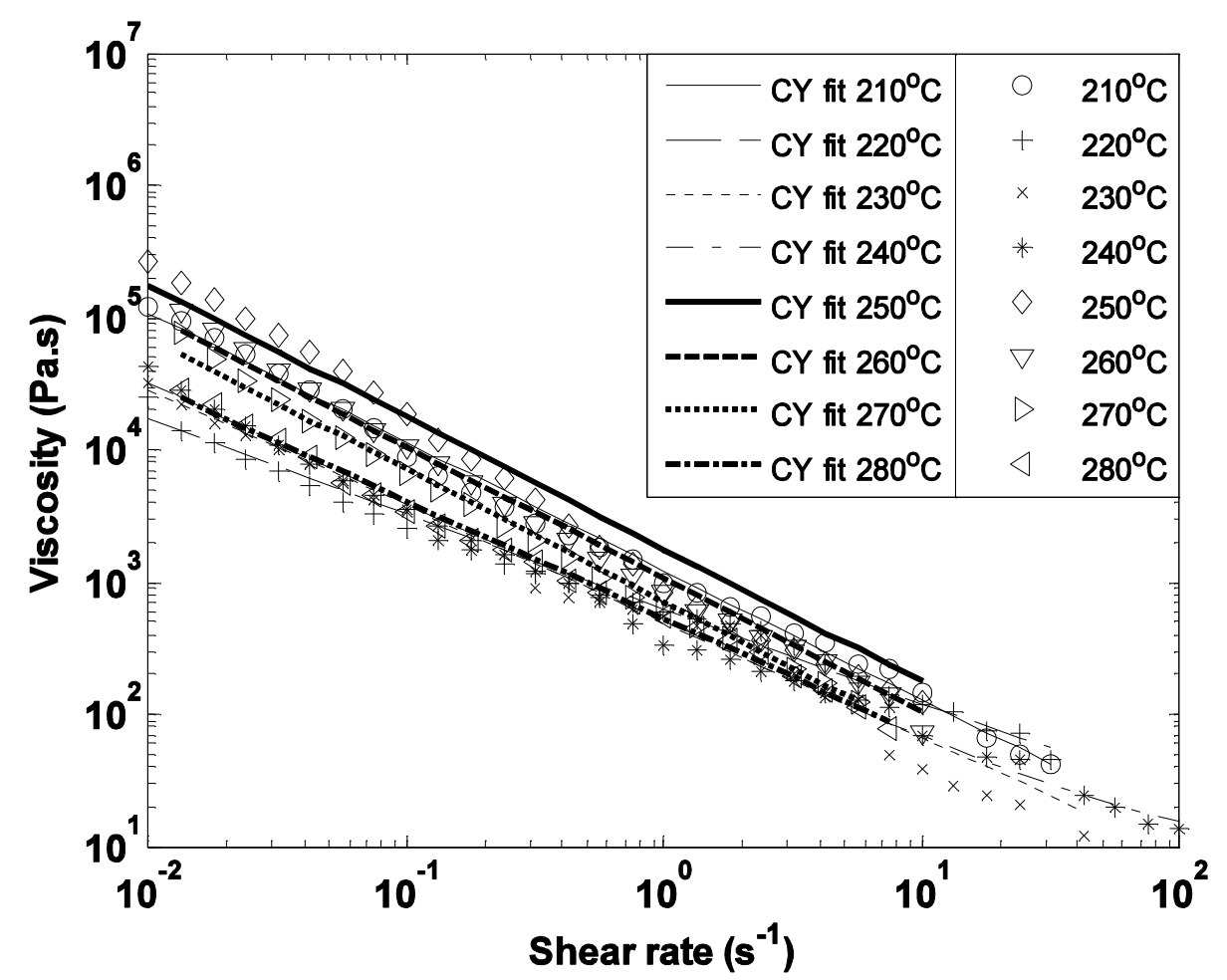

Figure 7: Flow curves of mesophase pitch MP110HT437T6 with mesophase content of 49 vol\% and $\mathrm{C} / \mathrm{H}=$ 2.20 .

\subsubsection{Empirical modelling}

Many equations have been developed to describe the viscosity-shear rate behaviour of nonNewtonian fluids. The simplest of these are the Bingham and power law models. The power law:-

$\eta=K_{p} \dot{\gamma}^{n-1}$

where $K_{p}$ is the consistency index and $n$ is the flow behaviour index, fits the data of samples with mesophase contents above $30 \%$ quite well but for the others the fit is only approximate. However, merely to emphasise the increasing shear thinning character with increasing $\mathrm{C} / \mathrm{H}$ ratio or mesophase content the values of the flow index, $n$, are shown in Figure 8 . They decrease (i.e. show more shear thinning character) as the $\mathrm{C} / \mathrm{H}$ ratio and mesophase content increase.

Other empirical expressions can model more precisely shear thinning character, where the viscosity may show a plateau at high, low or both regions of shear rate. e.g. the Cross [17], Herschel-Bulkley [18] and Carreau-Yasuda [19] equations. All of these were applied to the 
data and fitted with varying degrees of success. The one that gave the most accurate fit was the Carreau-Yasuda [19] empirical equation

$\frac{\eta-\eta_{\infty}}{\eta_{0}-\eta_{\infty}}=\left(1+(\lambda \dot{\gamma})^{a}\right)^{\frac{n-1}{a}}$

where $\eta_{0}$ and $\eta_{\infty}$ are the temperature-dependent zero-shear and infinite-shear viscosity, and $n$ is a flow index as in the power-law model. It has been proposed that $\lambda$ represents the viscous relaxation time, which is the time over which the viscosity changes from Newtonian to shearthinning, and $a$ is commonly referred to as the "Yasuda" constant which describes this transition; it is inversely related to the width of the transition zone [20]. The lines in Figures 3 to 7 are the fits based on this equation. It can be seen that this model fits the data very well. The adjustable parameters were estimated by optimizing the curve fit. However, not all of the parameters vary in a systematic way with sample composition, or temperature. This is an inherent property due to the numerous adjustable parameters in the model [19]. The CarreauYasuda parameters for two of the pitches are included in the supplementary material as examples.

\subsubsection{Temperature Dependence}

The Arrhenius equation (3), most applicable to simple low molecular mass liquids, has been applied to isotropic pitches [21] [22] [23]. However it needs to be used with caution for these systems as shown below.

$\eta_{T}=K_{\eta_{T}} e^{\frac{E_{\eta}}{R T}}$ 


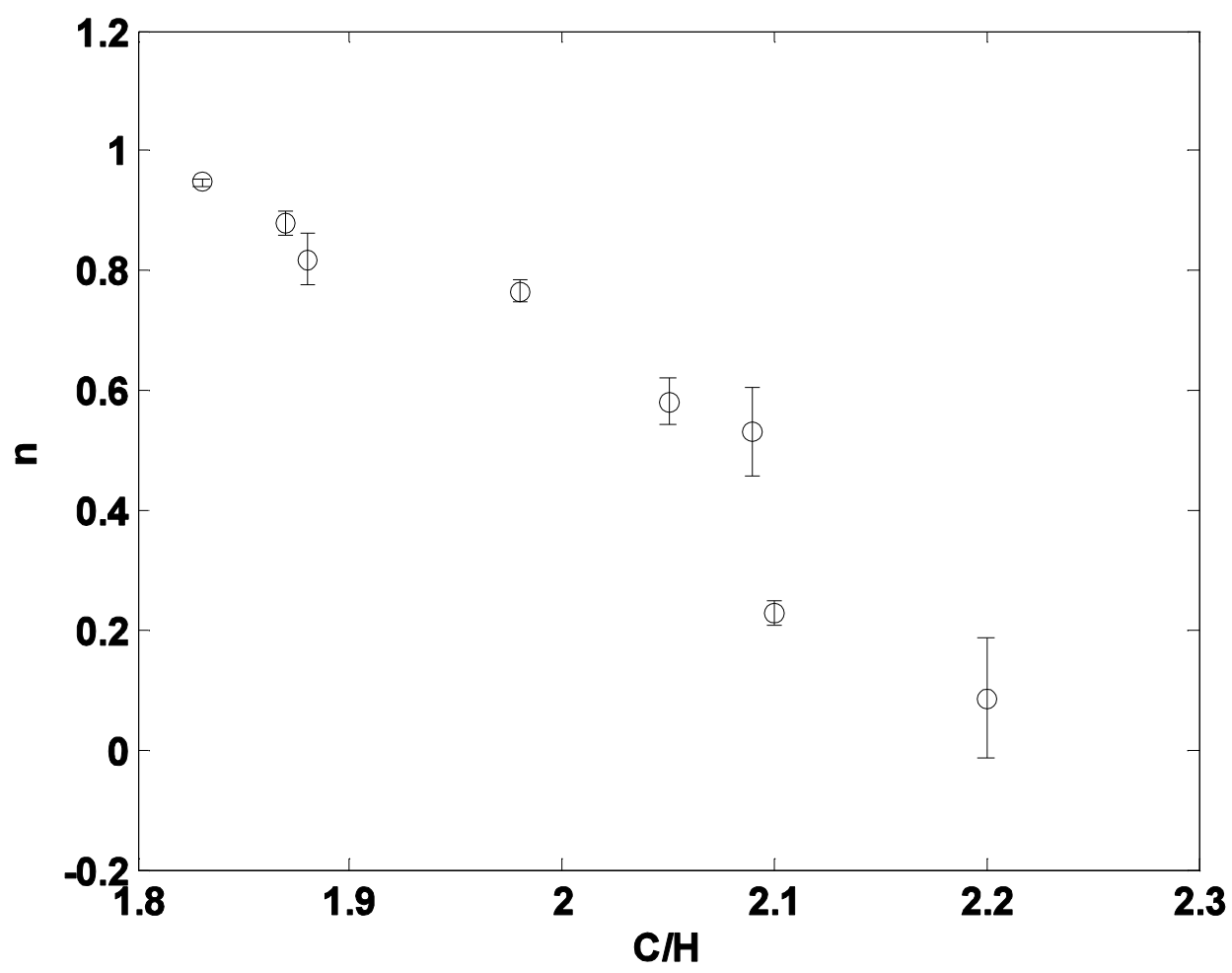

Figure 8: Power-law flow index variation with composition

The Carreau-Yasuda model was used to interpolate the temperature dependence of viscosity at various fixed shear rates for each sample and Arrhenius plots constructed. The activation energy did not vary much with shear rate, but did vary significantly as the $\mathrm{C} / \mathrm{H}$ ratio and mesophase content increased. The average value for each sample is shown in Figure 9 (a) except for the sample MP110HT437T6 $(\mathrm{C} / \mathrm{H}=2.20,49 \%$ mesophase $)$ which showed almost no temperature dependence. 

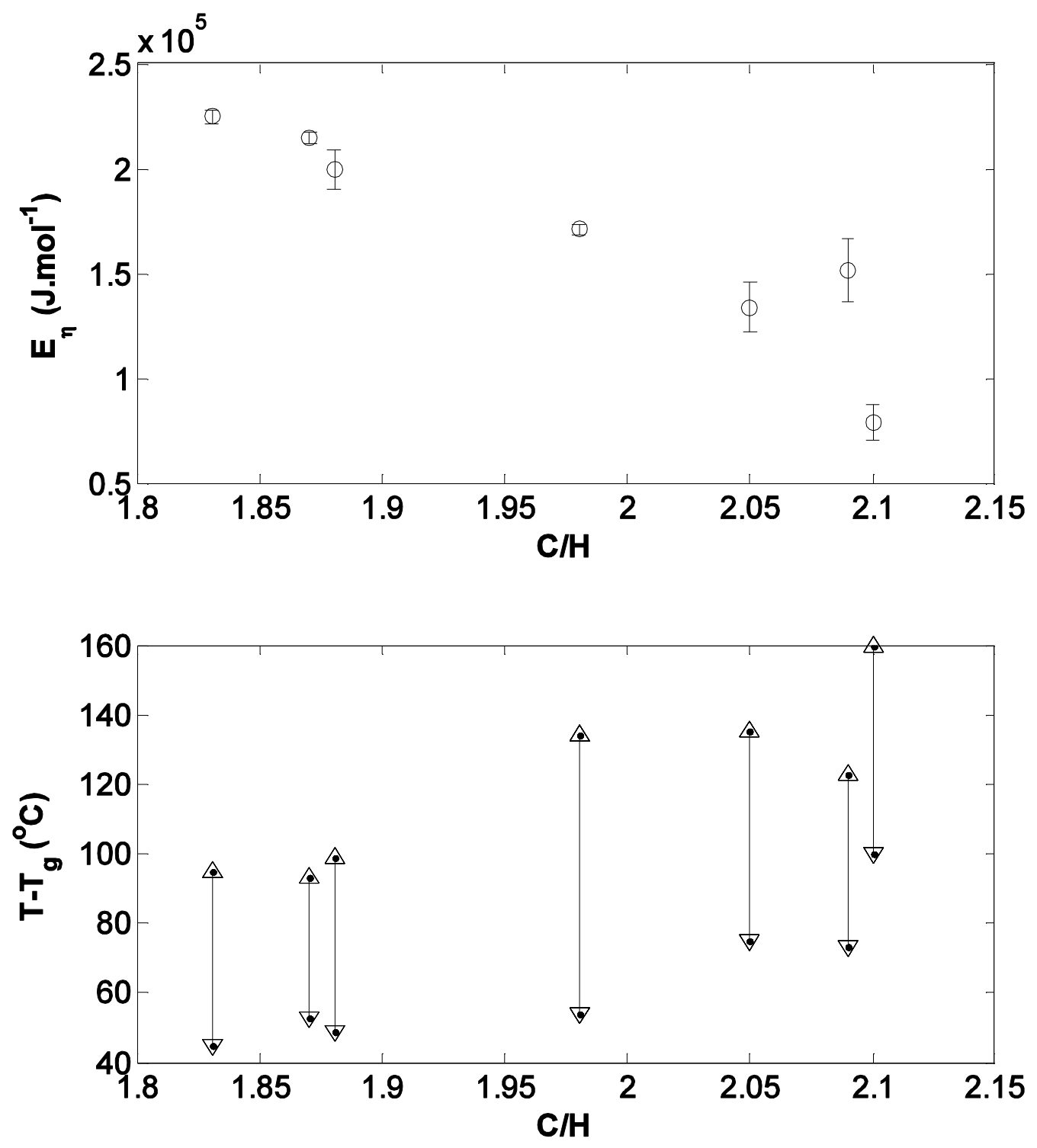

Figure 9: (a) Change in apparent activation energy with composition (above)

(b) Temperature range at which the apparent activation energy was measured for each sample (below)

The calculated apparent activation energies decrease with increased $\mathrm{C} / \mathrm{H}$ ratio, but the changes are not necessarily significant, because glass forming liquids that display such a wide variation of viscosity with temperature are better described by expressions such as the Fulcher-Vogel-Tammann-Hesse equation [24],

$\log \eta=A+\frac{B}{T-T_{g}}$

or the related Williams, Landel, Ferry equation (WLF) shown in its 'universal' form for polymeric systems in equation 5 [25]. 
$\log a_{t}=\log \frac{\eta}{\eta_{g}}=\frac{-C_{1}\left(T-T_{g}\right)}{\left(C_{2}+T-T_{g}\right)}$

The relevance of such approaches to pitch and mesophase pitch have been discussed by Rand [1], Turpin et al. [4], Sato et al. [21], Khandare et al. [22] and Py et al. [26]. The values of T$\mathrm{T}_{\mathrm{g}}$ at which the flow curves were measured are shown in Figure 9 (b) and it is evident that with increasing mesophase content the ranges of measurement are increasingly distant from the relevant $\mathrm{T}_{\mathrm{g}}$. This arises because the flow measurements are restricted to a specific viscosity range. Thus, the activation energies have been determined at different relative positions on the overall viscosity-temperature curve which spans many orders of magnitude. Figure 10 further illustrates this effect. The solid line is the prediction of the 'universal' WLF equation. The data for the isotropic starting pitch, MP110, $\mathrm{C} / \mathrm{H}=1.83$, fall parallel to this line, indicating different WLF C constants than the 'universal' values. However, for the sample with $38 \%$ mesophase, $\mathrm{C} / \mathrm{H}=2.1$, the data are located at much higher values of $\mathrm{T}-\mathrm{T}_{\mathrm{g}}$ where the WLF prediction would suggest that the continuous isotropic phase would be of very low viscosity. The viscosity values lay some 2-3 orders of magnitude higher than the WLF line. This shows most clearly that the influence of the dispersed mesophase on the viscosity at all shear rates is much greater than the effect of temperature in the temperature ranges employed for measurement. The WLF equation has been applied in oscillatory shear studies of these materials and this aspect will be reported in a separate publication.

For the pitches with 27 and 26 vol\% mesophase, $\mathrm{C} / \mathrm{H}=2.05$ and 2.09 respectively, Figures 4 and 5 (and also the sample with only 13 vol\% Mesophase in the supplementary material) at temperatures of measurement far from the isotropic phase $T_{g}$, the flow curves display zero and infinite shear viscosity plateaus. However, when the temperature of measurement is closer to the glass transition temperature of the isotropic phase, these plateaus are not clearly evident. At mesophase content greater than 30\%, however, there is a transition towards a monotonic shear-thinning regime, shown in Figures 6 and 7. In Figure 7 the log viscosity is almost linearly related to the log shear-rate. This suggests that there is a structure with a relatively longer relaxation time which can break down somehow at low shear-rates. However, because the flow measurements have been made at different $\mathrm{T}-\mathrm{T}_{\mathrm{g}}$ ranges the change in behaviour may be partly a result of relative temperature changes in addition to structural ones. The shapes of the flow curves are thus dependent on the structural character, as well as the relationship to the glass transition temperatures, which in the case of the two- 
phase systems is critical. The kink type of transition, shown here for the materials with mesophase contents of $20-30 \%$, has also been observed for synthetic $100 \%$ mesophase material and was attributed to the change in molecular orientation and a reduction in the domain size of the polydomain structure [10]. In the two phase mesophase pitches investigated in this paper, this will not be the case as there is no continuous mesophase; but break up and elongation of liquid crystal spheres is a possibility and should give a similar rheological response.

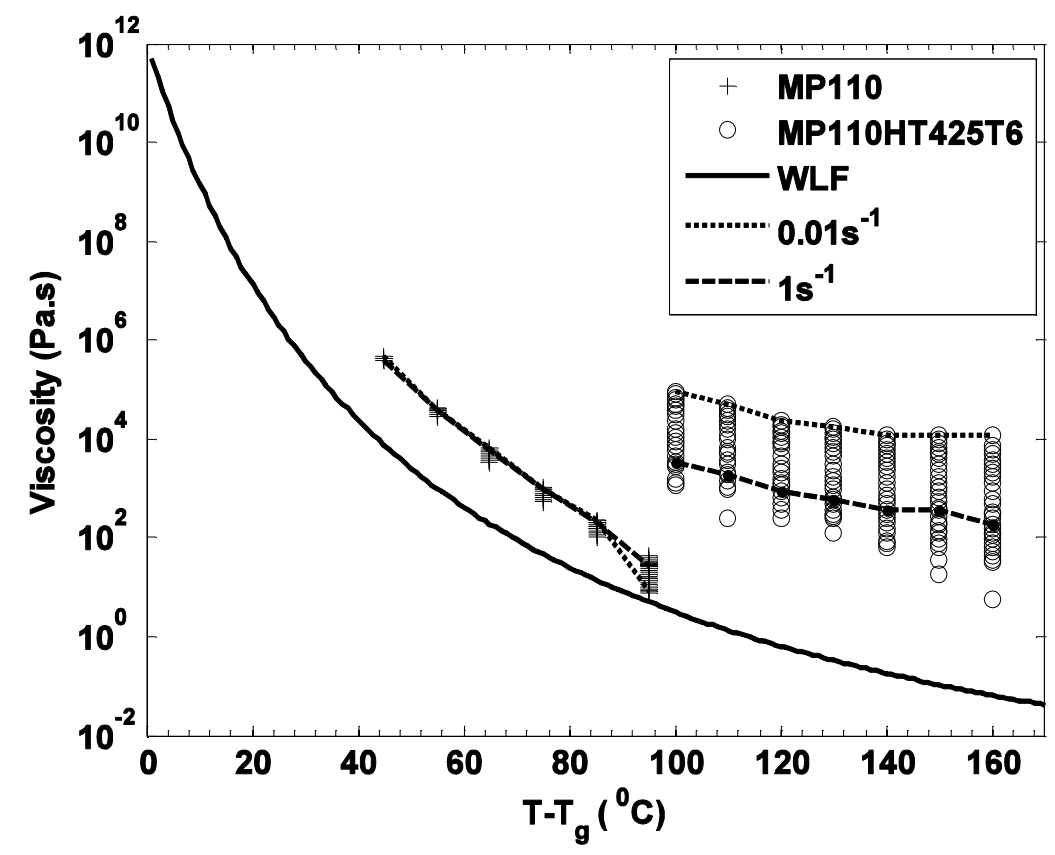

Figure 10: The 'Universal' WLF viscosity-temperature relation for polymers as an indication of the temperature dependence of glass-forming systems and the values for the initial isotropic pitch and a sample with significant amounts of mesophase. The points indicate the viscosity values at different shear rates

\section{Discussion}

Although the empirical Carreau-Yasuda model gives an excellent fit to the experimental viscosity data it does not assist in understanding the structural basis for the flow behaviour. The increase in shear thinning behaviour is quite similar to that of suspensions and some emulsions. Inspection of the $\mathrm{T}-\mathrm{T}_{\mathrm{g}}$ values in Figure 10 reveals that viscosity measurements were all made at temperatures above the $\tan \delta$ transition of the mesophase and thus all the systems are emulsions in principle. However, if the viscosity ratio of dispersed to continuous phases is high, they may behave more like suspensions. A factor that could contribute to 
solid-like behaviour is the possible presence of discotic columnar phases. However, the wide range of molecular mass that exists in the carbonaceous mesophase would suggest that such phases would not exist.

The rheology of emulsions has been discussed by Derkach [27] and Barnes [28]. The viscosities of emulsions depend strongly on the volume fraction of the dispersed phase, the viscosity ratio of the two phases and the Capillary number, $\mathrm{Ca}$ which is the ratio of the driving force for deformation (the shear stress) to the interfacial resistance.

$$
C a=\frac{\eta_{c} \dot{\gamma}}{\sigma / r}
$$

Where $\eta_{c}$ is the continuous phase viscosity, $\dot{\gamma}$ is the shear rate, $\sigma$ the interfacial tension and $\mathrm{r}$ the droplet radius. In the case of the mesophase pitches investigated here whilst estimates can be made of the continuous phase viscosity, the interfacial tension is unknown. The particulate QI attached to the mesophase surfaces raises the interfacial tension, increases the interface elasticity and restricts particle coalescence. The effect is to reduce the value of the capillary number. Unfortunately these interfacial values are unknown for the mesophase-QI system.

Taylor [29] showed that the degree of deformation of spherical drops was proportional to the capillary number at constant viscosity ratio, the latter ratio being less important than the magnitude of the continuous phase viscosity and shear rate within the formulation of the capillary number. Thus for the systems presented here deformation is more likely at low mesophase contents with large drops and at high shear rates. The deformation of mesophase spheres into oblate spheroids in a coal tar pitch such as this one where the mesophase spheres are stabilised by the QI attached to the surfaces was demonstrated by Collett \& Rand [11], but at much higher temperatures (around $400{ }^{\circ} \mathrm{C}$ ) than the temperatures of measurement employed here.

The breakup of droplets under shear is determined by both the capillary number and the viscosity ratio, as shown by Grace [30] and Jackson and Tucker [31]. A critical capillary number exists which decreases with increasing viscosity ratio to a minimum at a ratio of about 4, above which droplets are stable. However, it was later shown [30] that this critical value can be much lower in concentrated emulsions, because the interaction of the drops destabilises them, and to account for this a modified mean field version of the capillary 
number is required in which the emulsion viscosity replaces the continuous phase value and the viscosity ratio is replaced by that of the dispersed phase to the emulsion viscosity. The minimum in the mean field critical capillary number with this modified viscosity ratio now moves progressively to higher values of the viscosity ratio as the dispersed phase concentration increases.

The mesophase has significantly higher viscosity than the continuous phase since its $T_{g}$ value is higher as demonstrated by the difference in the $\tan \delta$ values for the two phases (Table 2). Some agglomeration of the mesophase drops without coalescence is also possible and increasing shear rates could break up the agglomerates also contributing to the shear thinning character. This effect may be more significant where the mesophase viscosity will be high and the spheres may behave more like hard particles.

The Krieger-Dougherty model is widely used to describe the variation of viscosity with volume fraction of dispersed phase $(\varphi)$ over a wide range; it however does not take into account particle interaction. The model assumes a hard-sphere suspension with random packing in a Newtonian fluid.

$\eta_{r}=\frac{\eta(\varphi)}{\eta(0)}=\left(1-\frac{\varphi}{\varphi_{m}}\right)^{-[\eta] \varphi_{m}}$

The intrinsic viscosity of the suspension, [ $\eta$, is 2.5 for a monodisperse hard sphere suspension. The maximum packing fraction, $\varphi_{m}$, is often assumed in studies to equal 0.630.64 , i.e. that of a random close-packing of monodisperse spheres.

In studies of colloidal systems with particle agglomeration giving rise to shear thinning behaviour, the approach has been to assume a maximum packing fraction for hard spheres and determine the effect of shear rate on the effective volume fraction of the dispersed phase. In such cases, the effective volume fraction at low shear rate is found to be higher than the true value due to the agglomeration of particles. Decreases in effective volume fraction with increasing shear rate are then attributed to the destruction of agglomerates.

In rheological studies of emulsions the Krieger-Dougherty equation has also been adopted and is most appropriate when the ratio of the viscosity of the dispersed phase to that of the 
continuous phase tends to infinity. When this is not the case, the viscosity ratio should be taken into account and Pal [32] derived the modified equation 8.

$\eta_{r}\left[\frac{\eta_{r}+5 K}{2+5 K}\right]^{3 / 2}=\left(1-\frac{\varphi}{\varphi_{m}}\right)^{-[\eta] \varphi_{m}}$

Application of these models to the viscosity data here is difficult because as the volume fraction of mesophase increases, in principle so does the composition of the continuous phase isotropic pitch and its viscosity-temperature relationship and this is not known precisely. Separation was attempted, but ultimately proved unsuccessful, although it is known to be possible [13] [16] [33] [34]. However, for one sample, MP110HT437, with a mesophase volume fraction of 0.27 , the $\mathrm{T}_{\mathrm{g}}$ value was close to that of sample MP110HT400, both considered to represent the $\mathrm{T}_{\mathrm{g}}$ of the continuous phase. Also the temperature ranges of viscosity measurement overlapped. Hence the MP110HT400 material could be used as a model to derive data for the continuous phase within the mesophase pitch, MP110HT437. Sample MP110HT400 had a small amount of mesophase and significant QI fraction, shown in Table 2. In order to estimate the viscosity of the isotropic phase at each temperature and shear rate the influence of these dispersed phases was calculated assuming that the KriegerDougherty model describes this influence. The volume fraction of particulate QI was calculated assuming a density of $2.0 \mathrm{~g} \mathrm{~cm}^{-3}$.

Both equations 7 and 8 were applied to determine whether treating the material with $27 \%$ mesophase (MP110HT437) as a suspension of hard spheres or as an emulsion had any significant effect on the variation of effective volume fractions $\left(\varphi_{\text {eff }}\right)$ of the dispersed phase with shear. The values calculated for the isotropic phase viscosity of MP110HT400 were assumed to apply to the continuous phase of sample MP110HT437 at the same temperature and shear rate.

The effective volume fractions obtained at several temperatures and different shear rates, using equation 7, are shown in Figure 11 and should be taken as indicative of material microstructural changes rather than being absolutely correct. They are dependent upon the assumptions made in the derivation, namely the volume fraction of maximum packing and the assumptions made above in the estimation of the isotropic phase viscosity. 


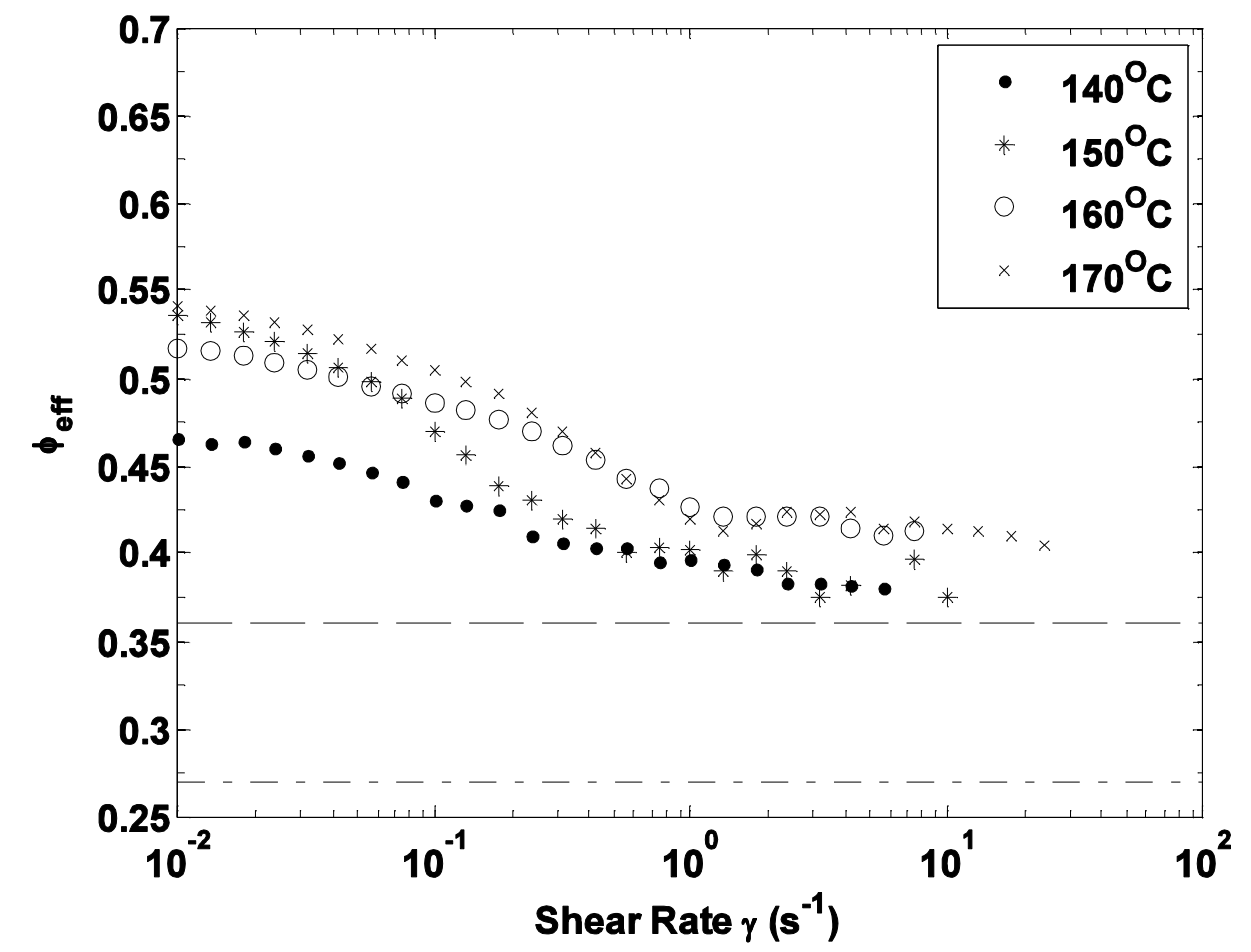

Figure 11: Effective volume fractions of mesophase pitch with 27 vol\% mesophase estimated using KriegerDougherty (equation 7), (- - = Mesophase and QI) (-.-= Mesophase)

Figure 11 shows that the effective volume fraction decreased with shear rate. At the lowest shear rates the calculated effective volume fraction was higher than the estimated volume fraction of mesophase and particulate QI (dashed line). Although the values are not accurate the effect appears real and it points towards some agglomeration of the mesophase spheres. Thus, shear induced de-agglomeration is a feasible process in these systems. In this respect it is interesting that the effective volume fraction determined at high shear rates reduced more or less to the volume fraction calculated for the mesophase and particulate QI. There is some variation in the effective volume fractions determined at different temperatures.

To apply the Krieger- Dougherty equation modified for emulsions (equation 8) the relative viscosities, $\mathrm{K}$, of the phases at each temperature are required. It was assumed that the mesophase viscosity could be described by the WLF equation. Khandare et al. [22] determined WLF parameters for a mesophase pitch and it was assumed that they would be a reasonable approximation for the viscosity of the mesophase in sample MP110HT437, sufficient enough to estimate the viscosity ratios, K. The WLF constants are slightly different from the universal values given above. An estimate of the $\mathrm{T}_{\mathrm{g}}$ of the mesophase was also required and was approximated from the trend of the tan $\delta$ temperature and $\mathrm{T}_{\mathrm{g}}$ values of the 
other pitches (isotropic fractions). The estimated ratios $(\mathrm{K})$ range from 150 to 20 (various shear-rates) over the temperature range $140{ }^{\circ} \mathrm{C}$ to $170{ }^{\circ} \mathrm{C}$.

Figure 12 shows the variation in effective volume fraction of the mesophase from the emulsion model. The trend is almost exactly the same but with some small changes to the magnitude of the effective volume fractions estimated. This suggests that in this range of mesophase content and temperature of measurement, the systems behaved like agglomerated hard sphere suspensions, probably a result of the strong stabilising effect of the particulate QI. The values of $\mathrm{K}$ above are very much larger than that at which drops are stable against drop breakup as obtained from the analysis of critical capillary radii and according to Jansen et al [35] the normal capillary number definition is appropriate for concentrations of dispersed drops up to about $30 \%$ as here. Thus treating this particular system as an assembly of hard particles is probably justified.

The pitches with higher mesophase volume fractions, which could only be measured at higher (T-Tg) show very much enhanced shear thinning character and for these the assumption of hard sphere character may no longer be applicable. To assess the emulsion behaviour the mean field capillary number is now more appropriate. This cannot be calculated with the limited data available but estimates of the mean field viscosity ratios $\mathrm{K}_{\text {mean }}$ can be made. For the sample with the highest mesophase content (49\%) that displays the strongest shear thinning character, the $K_{\text {mean }}$ values vary from about 1 to $10^{-4}$ at temperatures of 210 and $280{ }^{\circ} \mathrm{C}$, dependent upon shear rate and so whether the $\mathrm{Ca}_{\text {mean }}$ exceeds the critical value will depend very much on the interfacial tension and the system viscosity. The latter value could be high enough to push the system above the critical capillary number and thus it seems possible that shear induced breakup of the mesophase could occur increasingly as the shear rate increases. In support of this view, the resemblance of the flow curves in Figure 7 to those in the emulsions showing droplet break up modelled by Jansen et al [35] is striking. 


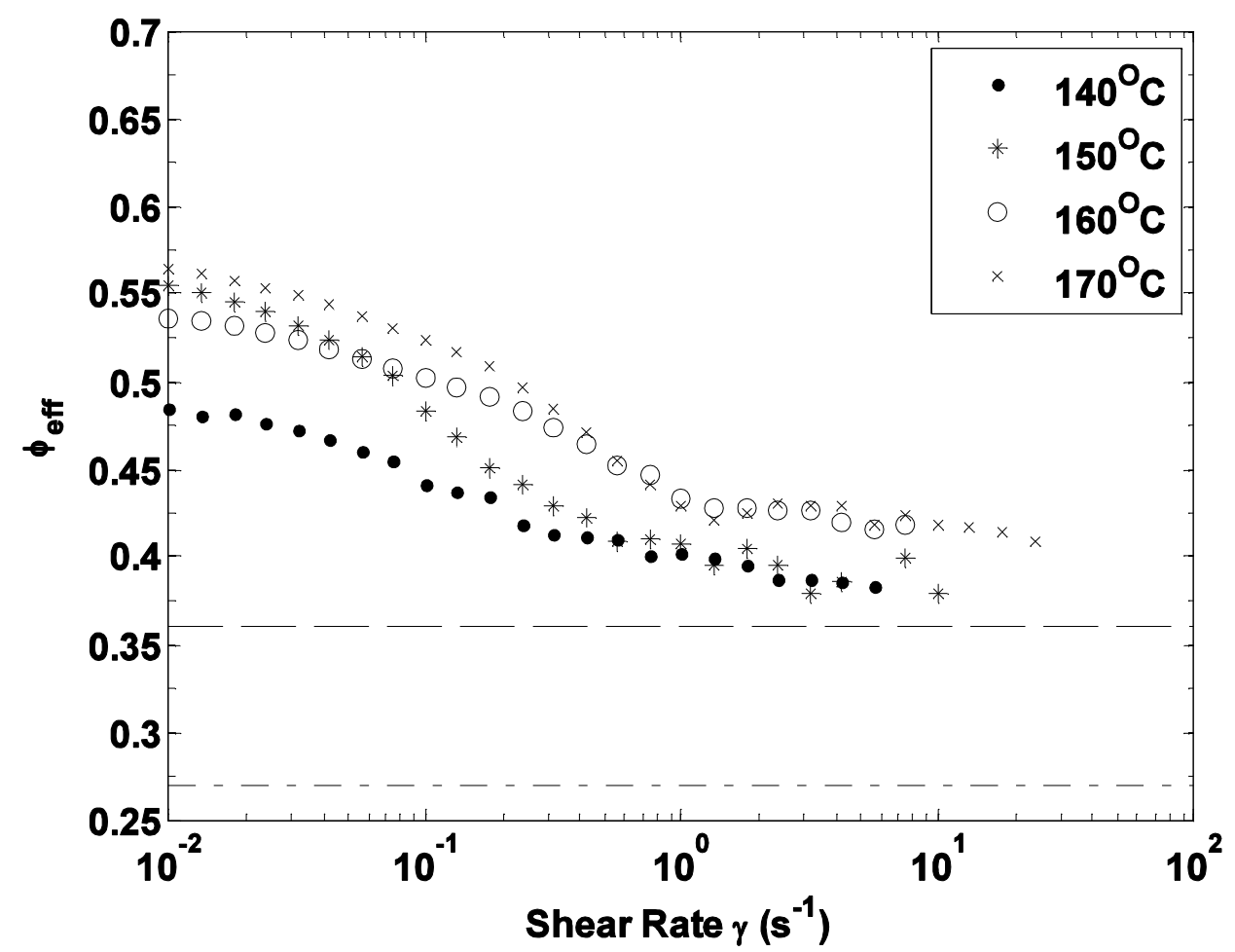

Figure 12: Effective volume fractions of mesophase pitch with 27 vol\% mesophase estimated using the modified Krieger-Dougherty model (equation 8), (- - = Mesophase and QI)(-.-= Mesophase)

\section{Conclusions}

A series of coal tar pitches heat-treated to increasing mesophase content and $\mathrm{C} / \mathrm{H}$ ratio were examined rheologically. The rheological behaviour was near-Newtonian (with a very small shear thinning character at high shear rates) in the isotropic pitches and ones with very small volume fractions of mesophase; for these the greatest effect on the viscosity was the measurement temperature, with little shear rate dependence. In contrast, increasingly stronger shear thinning character appeared as the mesophase content increased and the effect of shear rate on viscosity dominated over the effect of temperature. This was mainly due to the interactions between the mesophase spheres. The empirical Carreau-Yasuda model gave a good fit for all samples. At intermediate volume fractions of mesophase (0.2-0.3) the systems were modelled by the Krieger-Dougherty equation, and its emulsion analogue using an estimated value for the viscosity ratio of the two phases. Since similar behaviour was shown by both models, it is considered that the pitches behaved effectively as 'hard' spheres in the region of measurement. The changes in effective volume fraction determined from the model indicate agglomeration at low shear rates and break up of agglomerates as the main 
contribution to the shear thinning behaviour observed. However, at mesophase contents greater than $30 \%$, measurements of viscosity could only be made at higher temperatures and this resulted in greater shear thinning character. It is tentatively suggested that this is a result of shear induced deformation and breakup of the dispersed phase. The results show that, because the composition and hence the glass transition temperatures of the phases change continuously as the volume fraction of mesophase increases, different mechanisms are in place in the region at which viscosity measurements can be made $\left(10-10^{6} \mathrm{~Pa} . \mathrm{s}\right)$ and thus no single rheological model can apply over the whole range of mesophase content and the temperature range required for measurement.

\section{Acknowledgements}

This work is based upon research supported by the South African Research Chairs Initiative of the Department of Science and Technology (DST) and the National Research Foundation (NRF). Any opinion, findings and conclusions or recommendations expressed in this material are those of the authors and therefore the NRF and DST do not accept any liability with regard thereto. Shatish Ramjee also thanks the PBMR company and NRF for financial support.

\section{References}

[1] Rand, B., 1987. Pitch precursors for advanced carbon materials - rheological aspects *. Fuel, 66(June), pp.1491-1503

[2] Bhatia, G., Aggarwal, R. and Chari, S., 1977. Rheological characteristics of coal tar and petroleum pitches with and without additives. Carbon, 15, pp.219-223

[3] Blanco, C., Fleurot, O., Menéndez, R., Santamaria, R., Bermejo, J. and Edie, D., 1999. Contribution of the isotropic phase to the rheology of partially anisotropic coal-tar pitches. Carbon, 37(7), pp.1059-1064

[4] Turpin, M., Cheung, T. and Rand, B., 1994. Controlled stress, oscillatory rheometry of a petroleum pitch. Carbon, 32(2), pp.225-230

[5] Menéndez, R., Blanco, C., Santamaria, R., Bermejo, J., and Edie, D., 1998. Chemical and rheological characterization of air-blown coal-tar pitches. Carbon, 36(7), pp.973-979 
[6] Daji, J., Turpin, M. and Rand, B., 1998. Viscoelastic behaviour of a heat treated isotropic pitch. Carbon, 36(9), pp.1406-1409

[7] Turpin, M., Cheung, T., and Rand, B., 1995. Controlled stress, oscillatory rheometry of mesophase-pitches. Carbon, 33(12), pp.1673-1679

[8] Kundu, S. and Ogale, A., 2007. Microstructural effects on the dynamic rheology of a discotic mesophase pitch. Rheologica Acta, pp.1211-1222

[9] Kundu, S. and Ogale, A.A., 2006. Rheostructural studies on a synthetic mesophase pitch during transient shear flow. Carbon, 44(11), pp.2224-2235

[10] Cato, A.D. and Edie, D.D., 2003. Flow behavior of mesophase pitch. Carbon, 41(7), pp.1411-1417

[11] Collett, G. and Rand, B., 1978. Rheological investigation of coal-tar pitch during its transformation to mesophase. Fuel, 57, pp.162-170

[12] Braga, C. P., Dutra, C. H. M. de C., Castro, L. D. de, and Andrade, C. T. de., 2009. Influence of heat and pressure treatment on the rheological behavior of petroleum pitches. Fuel, 88(5), pp.853-860

[13] Blanco, C., Santamarıa, R., Bermejo, J., and Menéndez, R., 2000. Separation and characterization of the isotropic phase and co- existing mesophase in thermally treated coal-tar pitches. Carbon, 38, pp.1169-1176

[14] Soule, E. R., and Rey, A.D., 2012. Modelling complex liquid crystal mixtures: from polymer dispersed mesophase to nematic nanocolloids. Molecular Simulation, 38(8-9), pp.735-750

[15] Soule, E. R., and Rey, A.D., 2012. Hedgehog defects in mixtures of a nematic liquid crystal and a nonnematogenic component. Soft Matter, 8(5), pp.1395-1403

[16] Benn, M., Pitch-Mesophase-Carbon Transformation Diagrams and the Fabrication of Carbon Materials, University of Sheffield, PhD Thesis, 1989

[17] Cross, M. M., 1965. Rheology of non-Newtonian Fluids: A New Flow Equation for Psuedoplastic Systems. Journal of Colloid Science, 20, pp.417-437

[18] Herschel, W. H., and Bulkley, R.,1926. Konsistenzmessungen von Gummi-Benzollösungen. KolloidZeitschrift,39: pp.291-300, 
[19] Jordens, K., Wilkes, G. L., Janzen, J., Rohlfing, D. C., and Welch, M. B., 2000. The influence of molecular weight and thermal history on the thermal, rheological, and mechanical properties of metallocene-catalyzed linear polyethylenes, 41, pp.7175-7192

[20] Karlsson, A. O., Ipsen, R., Schrader, K., and Ardö, Y., 2005. Relationship between physical properties of casein micelles and rheology of skim milk concentrate. Journal of Dairy Science, 88(11), pp.3784-97

[21] Sato, Y., Kitano, T., Inagaki, M., and Sakai, M., 1990. Viscous flow of carbon black dispersed pitches: the dependence on temperature and carbon black concentration. Carbon, 28(I), pp.143-148

[22] Khandare, P., Zondlo, J., Stansberry, P. and Stiller, A., 2000. Rheological investigations of pitch material: Part II: viscosity measurement of A240 and ARA-24 pitches using a high-temperature high-pressure rheometer. Carbon, 38, pp.889-897

[23] Nazem, F., 1980. Rheology of carbonaceous mesophase pitch. Fuel, 59, pp.851-858

[24] Larson, R.G., The Structure and Rheology of Complex Fluids, New York, Oxford University Press, 1999

[25] Williams, M., Landel, R. and Ferry, J., 1955. The temperature dependence of relaxation mechanisms in amorphous polymers and other glass-forming liquids. J. Am. Chem. Soc, 679(12), pp.3701-3707

[26] Py, X., Daguerre, E., Guillot, A., and Spinner, B., 1997. Alpha-Relaxation of an Isotropic Petroleum Pitch: A Controlled Stress and Strain Oscillatory Rheometry Study. Carbon, 35(7), pp.1013-1021

[27] Derkach, S., 2009. Rheology of emulsions. Advances in colloid and interface science, 151(1-2), pp.1-23

[28] Barnes, H., 1994. Rheology of Emulsion - a review. Colloids and Surfaces A: Physicochemical and Engineering Aspects, 91, pp.89-95

[29] Taylor, I. G., 1934. The Formation of Emulsions in Definable Fields of Flow. Proceedings of the Royal Society, 146, pp.501-523

[30] Grace, H. P., 1982. Dispersion Phenomena in High Viscosity Immiscible Fluid Systems and Application of Static Mixers as Dispersion Devices in Such Systems. Chemical Engineering Communications, 14(3-6), pp.225277

[31] Jackson, N. E., and Tucker III, C. L., 2003. A model for large deformation of an ellipsoidal droplet with interfacial tension. Journal of Rheology, 47(3), pp. 659-682 
[32] Pal, R., 2001. Novel viscosity equations for emulsions of two immiscible liquids. Journal of Rheology, 45(2), pp.509-520

[33] Singer, L. and Riffle, D., 1987. High-temperature centrifugation: application to mesophase pitch. Carbon, 25(2), pp.249-257

[34] Kim, C., Ryu, S., and Rhee, B., 1993. Properties of coal tar pitch-based mesophase separated by hightemperature centrifugation. Carbon, 31(5), pp.833-838

[35] Jansen, K. M. B., Agterof, W. G. M., and Mellema, J., 2001. Droplet breakup in concentrated emulsions. Journal of Rheology, 45(1), pp.227-236 


\section{Supplementary Material: Figures and Tables}

\section{Additional comments on the characteristic temperatures}

The increase in transition temperatures given in Table 2 prevailed up to a heat treatment temperature of $425{ }^{\circ} \mathrm{C}, \mathrm{C} / \mathrm{H}=2.10$, but the sample, MP110HT437T6 $(\mathrm{C} / \mathrm{H}=2.20)$, with a prolonged treatment at $437{ }^{\circ} \mathrm{C}$ had an isotropic transition temperature below that of those treated at $425{ }^{\circ} \mathrm{C}$ even though it had a significantly higher mesophase content. Repeat preparation and characterisation runs were performed under these conditions and the results were confirmed as a real effect. The reason is not known with any certainty, but it is tentatively proposed that at treatment temperatures beyond $425^{\circ} \mathrm{C}$, cracking of aliphatic side chains takes place releasing low molecular mass species, a proportion of which are retained in the reactor and condense into the residue and lower the characteristic temperatures. It is considered that such low molecular mass species are most likely to be incorporated into the continuous isotropic phase rather than the mesophase which will have higher average molecular mass and aromaticity. It interestig to note that similar behaviour was observed by Liedtke and Huttinger (Liedkte, v and Huttinger KJ (1996), Mesophase Pitches as Matrix Precursor of Carbon Fiber Reinforced Carbon: Mesophase Pitch Preparation and Characterization. Carbon, 34, no9, pp1057-1066) when opening their mesophase pitch preparation reactor at different temperatures allowing different degrees of incorporation of volatiles into the samples and consequent change in glass transition temperatures. 
Additional Flow curves of predominantly isotropic pitches.

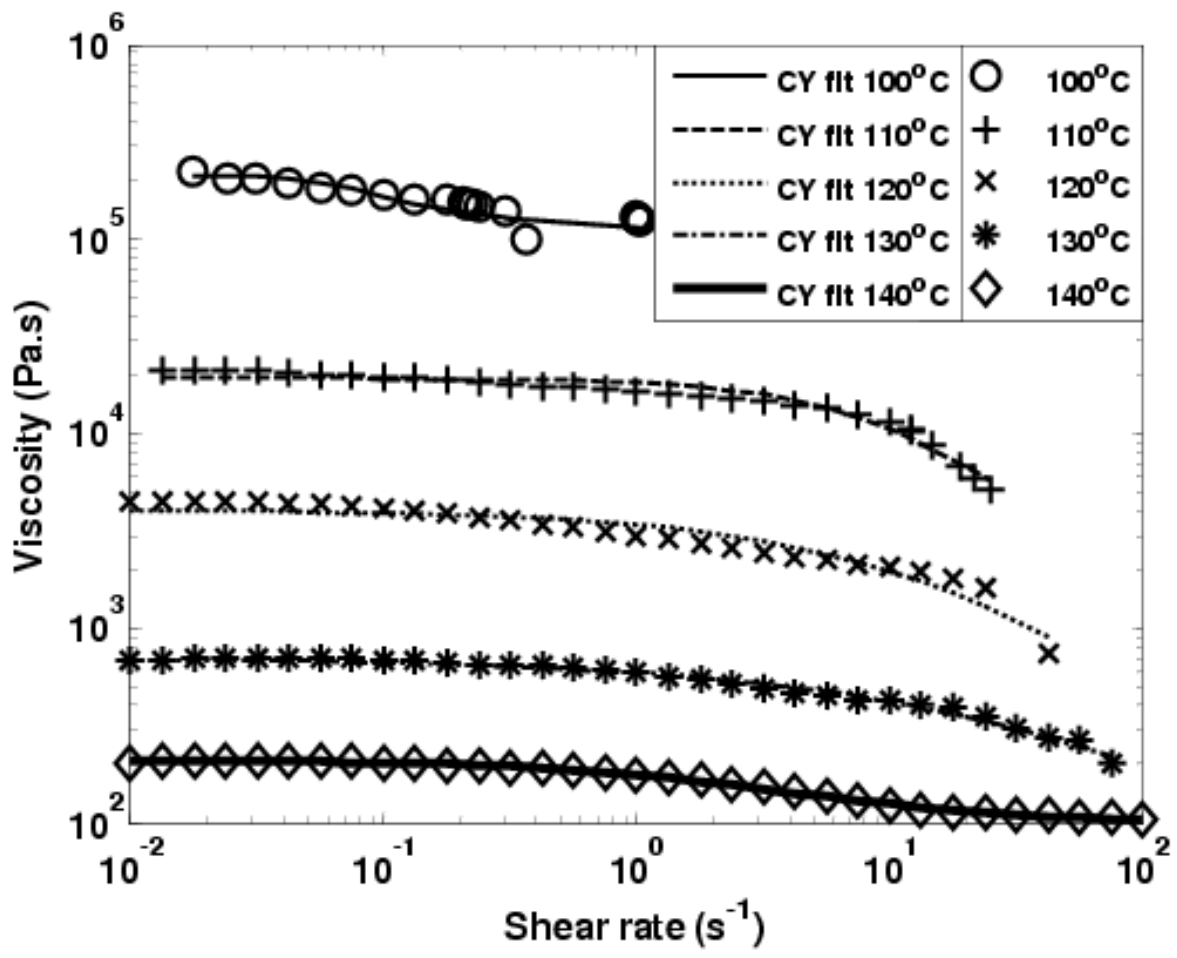

Figure S1: Flow curves of isotropic pitch MP110HT350 with $\mathrm{C} / \mathrm{H}=1.87$.

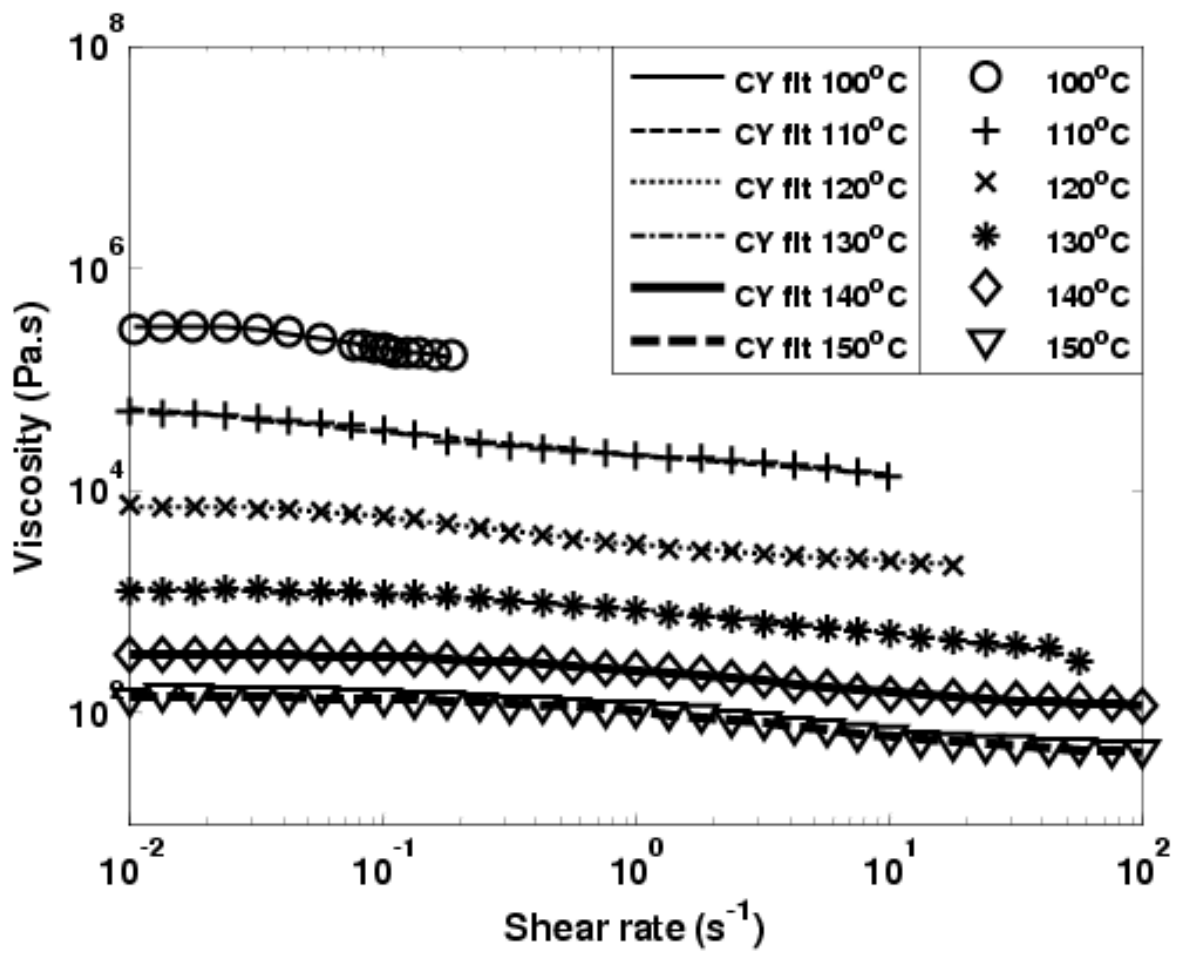

Figure S2: Flow curves of isotropic pitch MP110HT375 with $\mathrm{C} / \mathrm{H}=1.88$. 


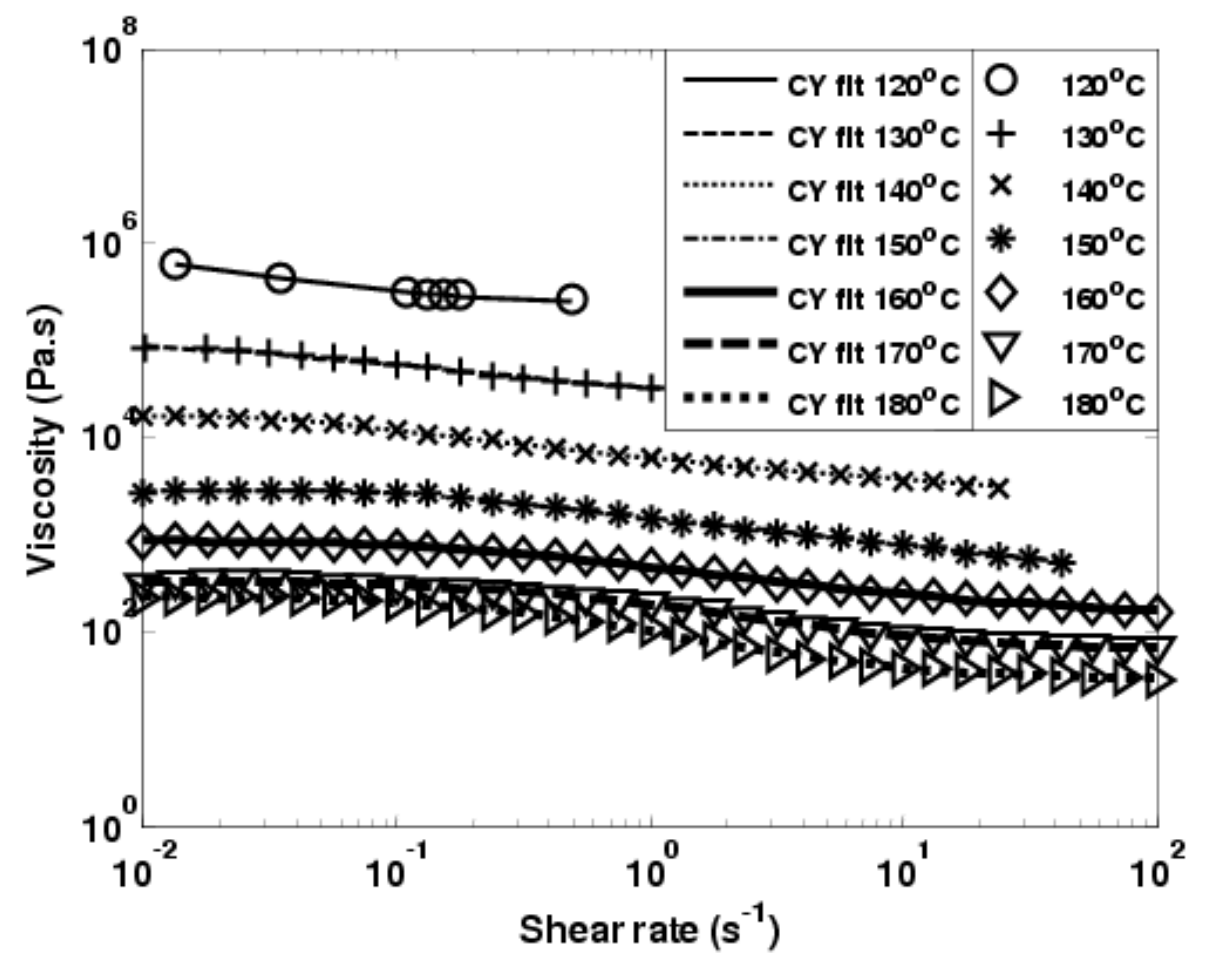

Figure S3: Flow curves of isotropic pitch MP110HT400 with $\mathrm{C} / \mathrm{H}=1.98$. and 13 vol\% mesophase.

Table S1: Carreau-Yasuda model parameters for MP110HT425T6 with mesophase content of 38 vol\% and C/H

$$
=2.10 \text {. }
$$

\begin{tabular}{|c|c|c|c|c|c|c|}
\hline $\begin{array}{c}\text { Temperature } \\
\left({ }^{\circ} \mathrm{C}\right)\end{array}$ & $\begin{array}{c}\eta_{0} \\
(\text { Pa.s })\end{array}$ & $\begin{array}{c}\eta_{\infty} \\
(\text { Pa.s) }\end{array}$ & $\begin{array}{l}\lambda \\
(\mathrm{s})\end{array}$ & $\begin{array}{l}a \\
(-)\end{array}$ & $\begin{array}{l}n \\
(-)\end{array}$ & $\begin{array}{l}\mathrm{R}^{2} \\
(-)\end{array}$ \\
\hline 180 & 94500 & 1170 & 45.4 & 1.88 & 0.05 & 0.996 \\
\hline 190 & 58800 & 115 & 62.0 & 1.54 & 0.14 & 0.998 \\
\hline 200 & 24600 & 24 & 51.5 & 1.76 & 0.13 & 0.995 \\
\hline 210 & 20200 & 142 & 47.6 & 1.49 & 0.00 & 0.995 \\
\hline 220 & 15800 & 19 & 66.0 & 1.18 & 0.10 & 0.997 \\
\hline 230 & 13400 & 24 & 76.4 & 2.01 & 0.13 & 0.998 \\
\hline 240 & 9980 & 46 & 65.9 & 1.75 & 0.00 & 0.993 \\
\hline
\end{tabular}


Table S2: Carreau-Yasuda model parameters for $\mathrm{MP} 110$ with $\mathrm{C} / \mathrm{H}=1.83$

\begin{tabular}{ccccccc}
\hline $\begin{array}{c}\text { Temperature } \\
\left({ }^{\circ} \mathrm{C}\right)\end{array}$ & $\begin{array}{c}\eta_{0} \\
(\mathrm{~Pa} . \mathrm{s})\end{array}$ & $\begin{array}{c}\eta_{\infty} \\
(\mathrm{Pa} . \mathrm{s})\end{array}$ & $\begin{array}{c}\lambda \\
(\mathrm{s})\end{array}$ & $\begin{array}{c}a \\
(-)\end{array}$ & $\begin{array}{c}\mathrm{R}^{2} \\
(-)\end{array}$ \\
\hline 80 & 444000 & 356100 & 22.7 & 2.33 & 0 & 0.829 \\
90 & 42000 & 0 & 2.62 & 0.771 & 0.771 & 0.926 \\
100 & 6520 & 0 & 0.622 & 0 & 0 & 0.987 \\
110 & 1050 & 0 & 0.447 & 0 & 0 & 0.983 \\
120 & 222 & 0 & 0.346 & 0 & 0.950 \\
130 & 31 & 9 & 1.30 & 0.977 & 0.619 & 0.765 \\
\hline
\end{tabular}

